\section{Pamphlet einer Uhr}

\author{
K. Mohtadi
}

Meine liebe Zeit, verehrter Ort, sehr geschätzte Gegenstände, meine Damen und Herren!

Es ist wohl nicht alltäglich, und es gehört auch nicht zur Tradition des Uhrengeschlechts, sich auf diese Art und Weise an Sie zu wenden. Ich gehe aber davon aus. Sie erlauben mir, als Inventar und langjähriges Mitglied des Rapportzimmers am Ende des Jahres 1985, dem ich vorweg für sein Verständnis für meine Lage danken möchte, einige Worte an Sie zu richten. Wie Sie wissen, sind wir Uhren gewöhnlich keine langweiligen und auch keine ärgerlichen Wesen, es sei denn, man setzt an uns gemäss unserer Natur nicht erfüllbare Forderungen. Ich hoffe jedenfalls, mit meinen Äusserungen, Ihre mir vertraute Geduld nicht allzusehr zu strapazieren. Aber nun zur Sache.

Bekanntlich finden wir Uhren uns sozusagen unmittelbar nach der Geburt und mit dem ersten Herzschlag in der menschlichen Gesellschaft zurecht. Denn wir sind nach unserer Konstruktion unmittelbar einsatz- und leistungsfähig. Und die Leistungsfähigkeit ist ja wertvollstes Merkmal und begehrteste Eigenschaft der Geschöpfe im menschlichen Sozialgefüge. Die Uhren geniessen zudem im allgemeinen von Anfang an eine klar umschriebene Identität, wenn man auch mit Bedauern feststellen muss, dass es auch gefälschte Uhren gibt. Ich bin nämlich eine "echte Schweizer Uhr». Zugegeben, eines ist uns Uhren gemeinsam: wir vermissen die Kindheit und die Erziehung, weswegen wir auch im Falle einer im Laufe des Lebens errungenen Wertsteigerung keine Beziehung $\mathrm{zu}$ unserem Schöpfer unterhalten und unter uns ebenfalls keinen näheren Kontakt pflegen. Dies ist auch der Grund warum wir, obgleich in menschlicher Gesellschaft angepasst, unter uns durch die Taktlosigkeit oft einander auf die Nerven geben.

Ich beabsichtige hier aber nicht, liebe Zuhörer, Sie mit unseren entwicklungsgeschichtlichen und innerfamiliären Problemen zu langweilen, sondern lediglich festzuhalten, dass wir Uhren gemäss unserer Natur als Einzelgänger und Eigenbrötler meist isoliert von den Artgenossen das Leben verbringen und als antriebsgesteuerte Wesen vor allem auf Sie, meine Damen und Herren, angewiesen sind. Ich brauche Ihnen ja nicht näher zu erläutern, eine kleine Pendeluhr zu sein und an der Mauer vis-à-vis der Eingangstür des Rapportzimmers seit Jahren zu hängen; dies dürfte namentlich Ihnen, der gnädigen Zeit, dem verehrten Ort, den geschätzten Gegenständen, am ehesten bekannt sein.

Korrespondenz:

Dr. med. K. Mohtadi

Kantonale Psychiatrische Klinik

CH-4915 St. Urban
Ich genoss in dieser Position das Privileg, jahrein, jahraus, bei jeder Witterung, jedem lokal- und globalpersonellen Wechsel, das innerrapportzimmerliche Geschehen genau zu beobachten. Ich durfte mir auch die ganze Zeit nichts anderes erlauben, ausser mich aktiv und aufmerksam am ständigen Fluss des Lebens in diesem Raum zu beteiligen. Und in dieser Funktion brachte ich es im Laufe der Jahre zu viel Erfahrung und einer gewissen Reife, zu der wohl auch die Geduld gehört. Denn ich hatte während Jahren die Gelegenheit, junge und ältere Menschen verschiedener Nationalitäten und Mentalitäten kennenzulernen. Ich registrierte Tugenden und Ruchlosigkeiten. Ich vernahm Lobworte und Tadel, Würdigungen und Beleidigungen. Ich beobachtete Arroganz und Bescheidenheit, Reife und kindliches Kompetenzgerangel. Ich hörte mir schliesslich Argumente und leeres Geschwätz an. Als aktives Mitglied dieses Raumes habe ich jahrelang aktiv und direkt am Rapport teilgenommen und diesen mitgestaltet. Man akzeptierte mich und brachte mir Respekt entgegen. Ja, es gab einstweilen den einen oder anderen, der beim Anblick meines Antlitzes Gewissensbisse bekam, wenn er morgens verspätet diesen Raum betrat oder ihn frühzeitig verliess. Es gab einen, der sogar unabhängig von der Arbeitszeit und ohne einen offenkundigen Grund bei meinem Ansehen Herzklopfen und Schweissausbrüche bekam, dem auch mein tröstliches Zuwinken nichts half. Dann waren wieder andere, die unter Druck der gnädigen Zeit stehend mich ungeduldig aggressiv anglotzten.

Selbstverständlich verbitte ich mir, und es liegt mir wahrlich fern, die Damen und Herren zu kritisieren oder das mir anvertraute esoterische Wissen $\mathrm{zu}$ profanieren. Aber nehmen wir Sie, geschätzten Tisch, als Beispiel. Sie bieten in Ihrer Funktion seit Ihrem Stellenantritt den Damen und Herren die Möglichkeit, sich um Sie niederzulassen, an Sie anzulehnen, Ihre Berichte und anderen Papierkram auf Sie zu legen. Sie schirmen die zitternden Füsse und nervösen Beine des einen oder der anderen vor neugierigen Augen ab und vertragen sogar das Gewicht der müden Körper. Kurzum: Sie setzten Ihre Jugend in den Dienst der Menschen und nun, ergraut, gehen Sie dem Alter $\mathrm{zu}$, das $\mathrm{zu}$ unserem Wesen gehört. Und in diesem Schlachthof, in dieser Mühle und Webstube der Gedanken und Gefühle, wo man sich über die menschlichen Belange den Kopf zerbricht, Überlegungen aufstellt, Urteile auf Ihrem Rücken, geschätzter Tisch, fällt, hat sich keiner auch nur einmal Gedanken über Ihr statisches jämmerliches Dasein gemacht. Sie waren einst ein kräftiger Nussbaum, der den Kindern durch seine Frucht Freude bereitete, den Liebespaaren Schatten und den Einsamen ein Stück Geborgenheit in der Natur bot. Sie, von der Ungnade des Strassenverkehrs Betroffener, eine verarbeitete, scheinbare Leiche eines Baumes und dennoch wertvoller als manche lebenden Menschen und teurer als manches Menschenleben. Ein Trost ist Ihnen gewiss - das Beisammensein mit den jüngergebliebenen Stühlen. Wie viele Pflanzen sind nicht von hier, aus diesem Rapportzimmer kurz nach ihrem Verblühen entfernt und 
auf den Komposthaufen des Schicksals geworfen worden. Und dieses von Büchern und Zeitschriften verlassene, ehrwürdige Gestell, das verzweifelt die Arme nach jedem Papier ausstreckt und von der guten alten Zeit träumt. Dieses des Wissens verlustig gegangene und der neuen Bibliothek abgetretene, wie ein räudiges, blossgestelltes Büchergestell mit ungewisser Zukunft!

Ich wollte Ihnen, verehrte Zuhörer, bei dieser seltenen Gelegenheit eigentlich von mir erzählen. Es ist mir jedoch noch ein Bedürfnis, meine Bewunderung für die leidtragenden Archivschubladen dieses Rapportzimmers kundzutun, die Beherberger der Krankengeschichten, die nie unter deren Last jammern. Es gebührt auch dem grossen Leuchter Dank, der unermüdlich und ohne Zögern nach jeden Knopfdruck leuchtet und unser Sehvermögen verschärft.

Und ich, die kleine Schweizer Pendeluhr, hänge an der Mauer vis-à-vis der Eingangstür und stehe seit vier Jahren still in diesem Zimmer, wo man den Puls des Lebens palpiert und den verzweifelten, sehnsüchtigen Seufzer der Ausgebrannten aus den Archivschubladen vernimmt. Oh! Die frostige Kälte durchdringt meine Glieder. Die Ignoranz, die grosse Schwester der Verachtung, die impertinente Verlogenheit schlechthin. Vorbei ist die Jugend, verloren das Ticktack der Triumphe und mein Schweigen, noch die Mutter aller Schreie! Ich verbreite keine Kassandrarufe und verkünde keinen Weltuntergang. Ich zeige nicht fünf vor zwölf und auch kein fünf nach zwölf, meine Zeiger stehen still seit vier Jahren auf fünfzehnsechsundfünfzig, vier vor vier, dreiuhrsechsundfünfzig. Seither streicht die Zeit in vierundzwanzig Stunden lediglich für zwei Augenblicke mein Gesicht. Aber ich war während dieser Jahre nie tot und werde auch solange weiterleben, als ich an dieser Mauer, in diesem Raum hänge und vergesellschaftet mit Ihnen bin, meine Damen und Herren, liebe Zeit, verehrter Ort, geschätzte Gegenstände. Obschon ich scheinbar nicht funktioniere, aber existiere, bin ich doch die nackte Realität, nicht wahr?

Ich bin das beredte Zeugnis einer uferlosen Apathie, paradigmatische Projektion und Verkörperung der in euch beheimateten Innenuhr oder erfrorenen Dynamik des herrschenden Geistes meiner kleinen Welt! Kein zeitsensibilisierter Soldat, kein Offizier, nicht einmal die Frauen, deren Körper besser als jede Uhr funktioniert, rührten sich beim Anblick meiner stillstehenden Glieder. Den Gottesgelehrten, der auf Ewigkeit gerichtet ist, verstehe ich zu gut. Die Hände jenes zeitfürchtigen Fremdlings, der mit überwundenen Hemmungen, mich liebevoll berührte und aufs Herz untersuchte, befruchteten wie die dürre Wüste nicht. Er trug meinen halblebendigen Körper auf der Schulter, wie Jesus das Kreuz, zur Werkstatt, um mich in Gang zu setzen. Wie sollte auch ein zungenverkrüppelter Fremdling einer stillstehenden kleinen Schweizer Pendeluhr, die ich bin, zur Bewegung verhelfen. Der Techniker gab sich natürlich Mühe und hat das Seine getan, aber ich bin noch die seit vier Jahren stillstehende Uhr. Wohlgemerkt, ich bin eine echte Schweizer Pendeluhr, nicht aus edlem, aber doch aus gutem Geschlecht.

Aber was klage ich über mein Los, das dutzendmal begehrter ist als das des Telefons. Ich bin aus gutem Holz und Metall. Das Telefon - der Fluch einer automatischen Maschine! - vorn und hinten Kunststoffprodukt, verurteilt lebenslang zum Lauschen und Verkehr, zum Summen und Schrillen. Ein wirklich erbärmliches, manipuliertes, hintergangenes Dasein. Und die Telefonabkömmlinge, die Sucher, diese einäugigen rastlosen Hetzer mit pockigen Gesichtern, die in ihren Nestern, um am nächsten Tag funktionsfähig zu sein, bei roten Nachttischlampen ausruhen.

Meine liebe Zeit, verehrter Ort, geschätzte Gegenstände, meine Damen und Herren! In der Nacht vom einunddreissigsten Dezember neunzehnhundertfünfundachtzig wird die grosse Uhr unserer schönen Kirche um vierundzwanzig Uhr vierundzwanzig Mal kräftig schlagen, und die grossen Kirchenglocken werden den Anbruch eines neuen Jahres verkünden und mit ihren klangvollen Lauten die Luft des Dorfes und den Raum dieses Rapportzimmers erfüllen.

Aber ich, eine kleine, echte Schweizer Uhr, werde noch still an der Mauer vis-à-vis der Eingangstür hängen, mit meinen Zeigern auf nicht fünfvorzwölf und auch nicht fünfnachzwölf, sondern auf dreiuhrsechsundfünfzig, vier vor vier: oder werde ich doch noch bis Ende dieses Jahres durch einen Uhrmacher repariert, um wie früher das Rapportzimmer der Ärzte Tag und Nacht durch mein Ticktack mit Leben zu füllen?

Ich wünsche Ihnen gesegnete Weihnachten und ein schönes neues Jahr.

Die Pendeluhr

i.V. Ihr Mohtadi 